\title{
Metabolic and hormonal studies of Type 1 (insulin-dependent) diabetic patients after successful pancreas and kidney transplantation
}

\author{
R. Landgraf ${ }^{1}$, J. Nusser ${ }^{1}$, R. L. Riepl ${ }^{1}$, F. Fiedler ${ }^{1}$, W.-D. Illner ${ }^{2}$, D. Abendroth ${ }^{2}$ and W. Land ${ }^{2}$ \\ ${ }^{1}$ Department of Internal Medicine, Klinikum Innenstadt and ${ }^{2}$ Division of Transplant Surgery, Klinikum Grosshadern, \\ University of Munich, Munich, FRG
}

Summary. Long-term normalization of glucose metabolism is necessary to prevent or ameliorate diabetic complications. Although pancreatic grafting is able to restore normal blood glucose and glycated haemoglobin, the degree of normalization of the deranged diabetic metabolism after pancreas transplantation is still questionable. Consequently glucose, insulin, C-peptide, glucagon, and pancreatic polypeptide responses to oral glucose and i.v. arginine were measured in 36 Type 1 (insulin-dependent) diabetic recipients of pancreas and kidney allografts and compared to ten healthy control subjects. Despite normal $\mathrm{HbA}_{1}(7.2 \pm 0.2 \%$; normal $<8 \%)$ glucose disposal was normal only in $44 \%$ and impaired in $56 \%$ of the graft recipients. Normalization of glucose tolerance was achieved at the expense of hyperinsulinaemia in $52 \%$ of the subjects. C-peptide and glucagon were normal, while pancreatic polypeptide was significantly higher in the graft recipients. Intravenous glucose tolerance $(n=21)$ was normal in $67 \%$ and borderline in $23 \%$. Biphasic insulin release was seen in patients with normal glucose tolerance. Glucose tolerance did not deteriorate up to 7 years post-transplant. In addition, stress hormone release (cortisol, growth hormone, prolactin, glucagon, catecholamines) to insulininduced hypoglycaemia was examined in 20 graft recipients and compared to eight healthy subjects. Reduced blood glucose decline indicates insulin resistance, but glucose recovery was normal, despite markedly reduced catecholamine and glucagon release. These data demonstrate the effectiveness of pancreatic grafting in normalizing glucose metabolism, although hyperinsulinaemia and deranged counterregulatory hormone response are observed frequently.

Key words: Pancreas transplantation - Glucose tolerance - Islet hormone release - Counterregulatory hormones

\section{Introduction}

To prevent or ameliorate vascular and neurological complications normalization of glucose metabolism is necessary (Hanssen et al. 1986). So far the only way to achieve long-term normoglycaemia in Type 1 (insulin-dependent) diabetes is pancreatic grafting (Land and Landgraf 1987; Dubernard and Sutherland 1989; Groth 1989; Najarian et al. 1990). However, not all successfully transplanted diabetic patients have a complete normalization of their diabetic metabolism such as impaired glucose utilization after oral or/and intravenous glucose load (Östman et al. 1988; Landgraf et al. 1989; Diem et al. 1990a; Osei et al. 1990), hyperinsulinaemia (Diem et al, 1990a; Luzi et al. 1990) or persistence of defective counterregulatory hormonal responses to glycopaenia (Bosi et al. 1988; Landgraf et al. 1989; Diem et al. 1990b). The presence or absence of improvements of these metabolic and endocrine parameters are highly relevant in the judgement of the overall benefit of pancreas transplantation.

Therefore, a prospective study has been undertaken in pancreatic transplant recipients to evaluate glucose tolerance by measuring glucose, insulin, C-peptide, glucagon, and pancreatic polypeptide after oral and intravenous glucose load. In addition, hormonal counterregulation to hypoglycaemia was assessed by determining glucose, C-peptide, glucagon, growth hormone, prolactin, catecholamines, and cortisol during insulin-induced hypoglycaemia. In this study the responses of pancreas recipients were compared to non-diabetic healthy control subjects.

\section{Subjects and Methods}

Subjects Thirty-six Type 1 diabetic recipients of pancreas and kidney allografts using duct occlusion for segmental pancreatic grafting $(n=28)$ or pancreaticoduodenal-cystostomy for exocrine drainage $(n=8)$ all with iliac vessel anastomoses (Land et al. 1987), were studied one to 103 months after successful grafting (Table 1). A graft was considered successfully functional when there was no further insulin requiring therapy and nomal $\mathrm{HbA}_{1}$ levels and nomal daily blood glucose measurements. Immunosuppression was achieved in most patients with triple-drug therapy of azathioprine 
(25.75 mg daily), cyclosporin (whole blood trough levels 200-300 $\mathrm{ng} / \mathrm{ml}$ using polyclonal antibodies) and low dose prednisone (6士1 mg; $2-20 \mathrm{mg} / \mathrm{daily}$ ). Healthy volunteers of similar age/sex distribution and body mass index served as control subjects. All subjects gave their informed consent and the tests started after an overnight fast at 08.00 hours while on bed rest without taking immunosuppressive drugs. All tests were not performed on all subjects.

Oral glucose i.v. arginine tolerance tests. Oral glucose tolerance tests were performed on 36 pancreas recipients and 10 healthy control subjects (Control subjects 1 , Table 1). The pancreas recipients were tested prospectively every six months. $100 \mathrm{~g}$ glucose (i.e. $400 \mathrm{ml}$ Dextro-OGT Boehringer, Mannheim, FRG) was ingested within 5 min. An intravenous line was placed in an antecubital vein for blood sampling for glucose, C-peptide, insulin, glucagon, and pancreatic polypeptide determinations. Blood samples were taken before $(0 \mathrm{~min})$ as well as 30,60 , and $120 \mathrm{~min}$ after oral glucose load.

At $120 \mathrm{~min}$ an intravenous arginine infusion was started for $30 \mathrm{~min}$ ( $250 \mathrm{ml} 6 \%$ arginine solution $=15 \mathrm{~g}$ arginine) and blood was drawn at $125,130,140,150$, and $180 \mathrm{~min}$ after glucose load. This combined glucose/arginine test was designed to measure glucose-induced glucagon suppression and arginine-induced glucose-potentiation of insulin release as well as arginine-provoked glucagon secretion. Glucose tolerance was defined as normal when basal and $2 \mathrm{~h}$ venous blood glucose was less than $6.7 \mathrm{mmol} / \mathrm{l}$ (WHO criteria).

Intravenous glucose tolerance tests. In order to compare glucose utilization after oral glucose with the response after intravenous glucose 21 pancreas recipients were injected rapidly with glucose $(0.5 \mathrm{~g} / \mathrm{kg}$ body weight within $2 \mathrm{~min}$ ) and serum glucose, C-peptide, insulin, and glucagon were measured before $(0 \mathrm{~min})$ and $5,10,15,25,35,45$, 55 , and $65 \mathrm{~min}$ after glucose load. The glucose assimilation coefficients $(\mathrm{Kg})$ were caiculated using the slope of the linear regression equation for the natural $\log$ glucose concentration at the time of 10 to $65 \mathrm{~min}$. (diabetic $<0.9$, borderline 0.9-1.1, normal > $1.1 \% / \mathrm{min})$.
Insulin-induced hypoglycaemia. Twenty diabetic patients with successful pancreatic grafting and eight healthy subjects (Control subjects 2, Table 1) underwent insulin-induced hypoglycaemia tests. Two baseline values were collected ( -15 and $0 \mathrm{~min}$ ) before 0.075 IU/kg human insulin was injected i.v. as a bolus and blood was collected at $10,20,30,45,60,75,90$, and $120 \mathrm{~min}$ for measurements of glucose, C-peptide, glucagon, growth hormone, prolactin, epinephrine, nor-epinephrine and cortisol. The tests were performed (24 months) post-transplant. In two patients the tests were repeated 12 months post-transplant.

Methods Plasma glucose was measured by the glucose oxidase method using a Hitachi autoanalyzer (Boehringer, Mannheim, FRG). Stable $\mathrm{HbA}_{1}$ was determined by an electrophoretic method (Ciba-Corning, Munich, FRG; normal range: 5.5-8.0\%). Serum insulin and C-peptide concentrations were measured by a standard double antibody radioimmunoassay (I.R.E., Fleurus, Belgium). Insulin antibodies were not detectable in our patients. The blood samples for the determination of plasma glucagon according to Heding (1979), and catecholamines according to Passon and Peuler (1973) and Peuler and Johnson (1977) were transferred into prechilled tubes with the appropriate ingredients quickly centrifuged at $4^{\circ} \mathrm{C}$ and stored at $-70^{\circ} \mathrm{C}$. Growth hormone (von Werder 1975), prolactin (von Werder 1975), and cortisol (Stalla et al. 1981) determinations were measured by standard analytical procedures. Pancreatic polypeptide was determined by radioimmunoassay according to Riepl et al. (1990).

Statistical analysis. Data are given as means \pm SEM unless otherwise stated. The Mann-Whitney U test was used to test differences between graft recipients and control subjects. For the prospective study of oral glucose tolerance and islet hormone release the Wilcoxon signed-rank test for paired samples was applied. All tests were twotailed. Significance was considered at a $\mathrm{p}$ value $<0.05$.

Table 1. Clinical data of Type 1 (insulin-dependent) diabetic patients with pancreas allografts and of normal control subjects.

Pancreas recipients Control subjects (1) Control subjects (2)

$\begin{array}{ll}\mathrm{n} & 36 \\ \text { Age (years) } & 37 \pm 1(25-53) \\ \left.\text { BMI (kg/m }{ }^{2}\right) & 22.2 \pm 0.5(16.2-29.3) \\ \text { Duration of Diabetes (years) } & 25 \pm 1(13-41) \\ \text { Sex (male/female) } & 18 / 18 \\ \mathrm{HbA}_{1}(\%) & 7.1 \pm 0.1(5.5-8.1) \\ \text { Serum creatinine (mg/dl) } & 1.85 \pm 0.19(0.8-3.5) \\ \text { Time after pancreas } & 35 \pm 4(1-103) \\ \quad \text { transplantation (months) } & \\ \text { Immunosuppression } & \\ \text { CyA (alone) } & \mathrm{n}=1 \\ \text { CyA + Aza } & \mathrm{n}=11 \\ \text { CyA + Aza + Prednisone } & \mathrm{n}=24\end{array}$

$\begin{array}{ll}10 & 8 \\ 38 \pm 7(30-50) & 24 \pm 1(21-27) \\ 21.3 \pm 0.5(18.8-23.0) & 21.2 \pm 0.8(18.6-23.7) \\ - & - \\ 5 / 5 & 4 / 4 \\ 6.5 \pm 0.2(5.7-7.4) & 6.4 \pm 0.2(5.6-7.2) \\ 0.90 \pm 0.04(0.7-1.1) & 0.81 \pm 0.03(0.7-1.1) \\ - & -\end{array}$

(mean \pm SEM and range) 


\section{Results}

\section{Oral glucose-i.v. arginine tolerance}

\section{Cross-sectional study}

Although there were no further exogenous insulin requirements and the patients showed normal daily blood glucose profiles by self-monitoring and normal haemoglobin $A_{1}$ levels $(7.2 \pm 0.2 \%)$ at the time of testing, oral glucose tolerance was completely normalized in only $44 \%$, whereas the others had impaired glucose disposal (Fig. 1).

While C-peptide levels were within the normal range and differed between the patients with normal and impaired glucose utilization only at $60 \mathrm{~min}(\mathrm{p}<0.025)$, the insulin secretory response after glucose stimulation was markedly elevated in those pancreas recipients with normal glucose tolerance (at $30 \mathrm{~min} p<0.025$ and at $60 \mathrm{~min} \mathrm{p}<0.005$ ). After additional arginine stimulation insulin release was biphasic and higher in both diabetic recipient groups when compared to healthy control subjects. Glucagon levels were above the normal range in all patients during glucose-induced glucagon suppression and arginine-provoked release, although there was a high variability between patients. Basal pancreatic polypeptide (hPP) levels were significantly higher in pancreas/kidney recipients compared with control subjects $(12.8 \pm 7.5$ vs $29.2 \pm 5.5$ $\mathrm{pmol} / \mathrm{l} ; \mathrm{p}<0.01$ ). After glucose load hPP increased in transplanted individuals to a maximum of $43.7 \pm 9.3$ $\mathrm{pmol} / \mathrm{l}$ at $30 \mathrm{~min}$ and decreased to basal levels, while hPP remained unchanged in healthy control subjects (Fig. 2).
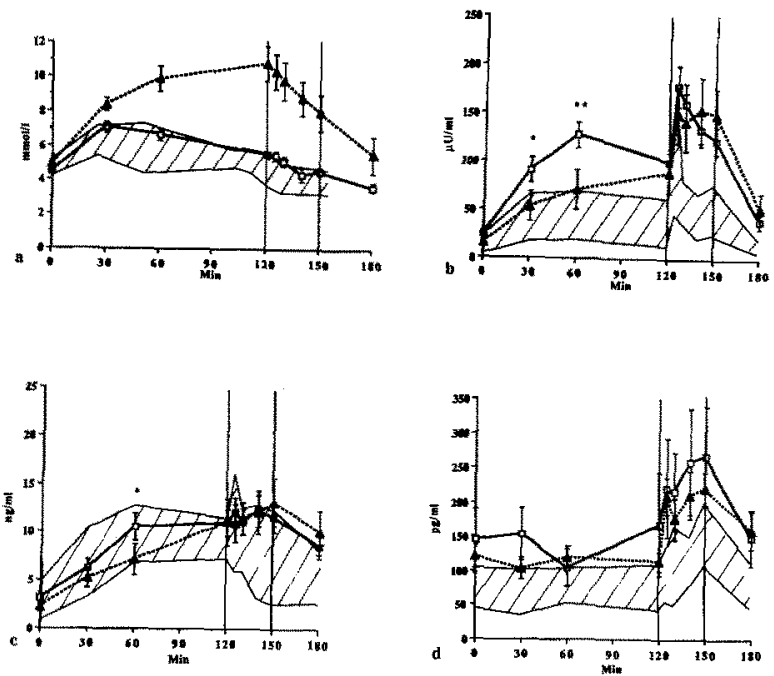

Fig. 1. Blood glucose (a), serum insulin (b), C-peptide (c), and plasma glucagon (d) after oral glucose (0-120 min) and i.v. arginine $(120-150 \mathrm{~min})$ in 36 pancreas and kidney recipients with normal $(n=16 ; 0-0)$ and impaired glucose tolerance $(n=20 ; \Delta-\Lambda)$. The shaded area indicates the mean $\pm S D$ in the normal subjects $(n=10)$. At all time points of the glucose curve there was a significant difference between the two groups of graft recipients $(p<0.025$ to $p<0.0001$ ). ${ }^{*} \mathrm{p}<0.025,{ }^{* *} \mathrm{p}<0.005$ for insulin and $\mathrm{C}$-peptide respectively.

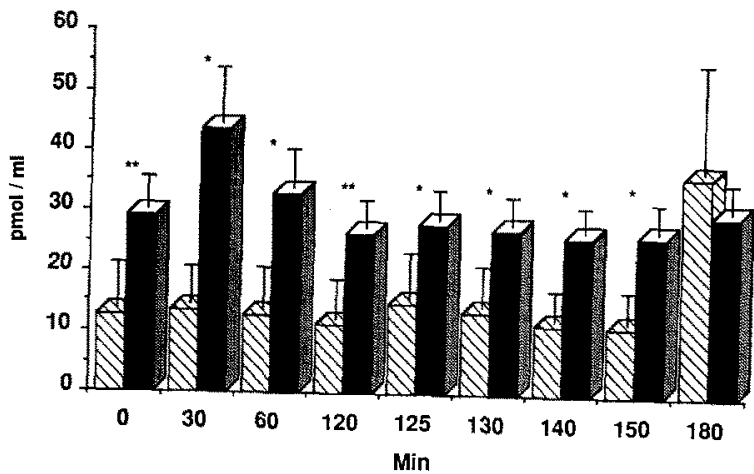

Fig. 2. Pancreatic polypeptide after oral glucose $(0-120 \mathrm{~min})$ and i.v. arginine $(120-150 \mathrm{~min})$ in kidney/pancreas graft recipients $(n=14 ;-1)$ and healthy control subjects $(n=10 ; \mathscr{L}) .{ }^{*} p<0.05$, ${ }^{* *} \mathrm{p}<0.01$

During arginine infusion in both groups hPP was unaltered. However, after cessation of arginine infusion hPP increased significantly $(\mathrm{p}<0.01)$ in the healthy control subjects but not in the transplanted group. Except at $180 \mathrm{~min}$ all pancreatic polypeptide levels were higher in the graft recipients.

\section{Prospective study}

Time-dependent integrated responses (0-120 min) of blood glucose, C-peptide, insulin, and glucagon after oral glucose are depicted in Figure 3. The areas under the timeconcentration curves obtained two months posttransplant were set to $100 \%$ and were compared to the values 1 to 7 years after successful grafting. Oral glucose tolerance did not deteriorate except temporarily at 2 years post-transplant $(p<0.05)$ although glycated haemoglobin remained normal (not shown). Insulin secretory response was very similar in the different time periods, while C-peptide levels remained the same except at 4 years, where it dropped significantly $(p<0.05)$. Glucagon response decreased markedly $(p<0.05) 4$ years post-transplant. Since polypeptide hormone levels are also dependent on renal function creatinine levels were analysed. They were slightly elevated (Table 1) but did not change during time, indicating a good and stable kidney graft function and suggest that decreased hormone levels are mainly due to reduced secretory capacity rather than changes in renal clearance. When following three pancreas recipients over more than 6 years post-transplant time-dependent integrated responses after oral glucose load, glucose tolerance remained stable independent of the initial graft function (Fig. 4). Also, $\mathrm{HbA}_{1}$ levels were normal throughout the observation period (not shown). Hormone response fluctuated considerably with a clear tendency toward reduced insulin secretory capacity in all patients by 5 years post-transplant. 


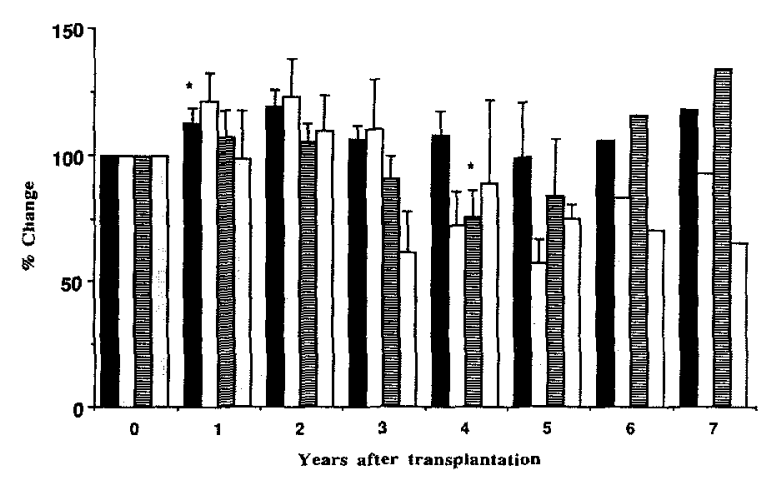

Fig. 3. Time-dependent integrated $(0$ to $120 \mathrm{~min}$ ) response after oral glucose load of blood glucose $(\square)$, insulin $(\square)$, C-peptide (ㅇ) , and glucagon (a) from 0 ( 2 months post-transplant) up to 7 years post-transplant $(0$ years $n=28 ; 1$ year $n=28 ; 2$ years $n=23 ; 3$ years $n=13 ; 4$ years $n=7 ; 5$ years $n=4 ; 6$ years $n=2 ; 7$ years $n=2$ ). The first values were set at $100 \%$. ${ }^{*} \mathrm{p}<0.05$
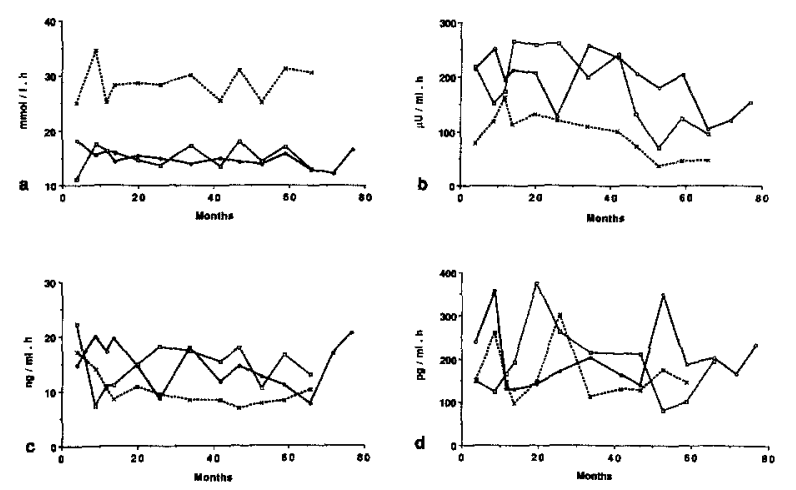

Fig. 4. Time course of integrated (0 to $120 \mathrm{~min}$ ) response after oral glucose load of blood glucose (a), insulin (b), C-peptide (c), and glucagon (d) in three graft recipients with the largest graft survival in the Munich series.

\section{Intravenous glucose tolerance}

Gastroparesis due to autonomic neuropathy might interfere with oral glucose tolerance, simulating normal glucose disposal. Therefore, i.v. glucose tolerance testing was performed in 21 graft recipients and compared to their oral glucose tolerance. Fourteen patients $(67 \%)$ showed normal glucose disappearance rates $(2.0 \pm 0.5 \% / \mathrm{min})$ and seven had borderline $\mathrm{Kg}$-values $(1.01 \pm 0.03 \% / \mathrm{min})$, none of them, however, was diabetic ( $\mathrm{Kg}<0.9 \% / \mathrm{min}$; Fig. 5). A biphasic glucose-induced insulin release pattern was noted in those patients with a normal glucose utilization. In contrast, patients with impaired glucose tolerance had much lower and monophasic insulin secretory profiles. The C-peptide levels increased also much more sluggishly in these patients. When the results of the i.v. and the oral glucose tolerance tests were correlated the following was found: normal values in both tests in eight patients, impaired glucose tolerance in both tests in four patients, normal oral glucose tolerance and impaired i.v. glucose tole- rance in three patients, and impaired oral glucose tolerance and normal i.v. glucose tolerance in six patients.
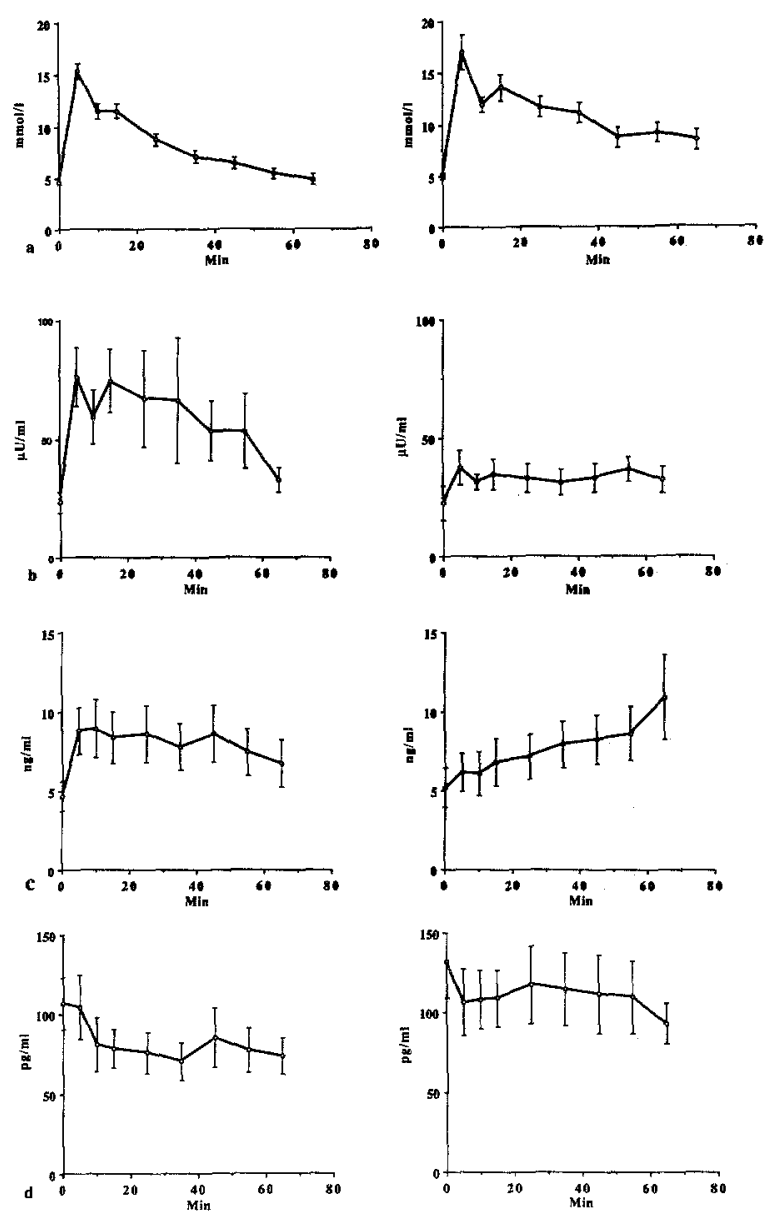

Fig. 5. Intravenous glucose tolerance tests with measurement of blood glucose (a), insulin (b), C-peptide (c), and glucagon (d) in graft recipients $(n=21)$ with normal (left; $n=14$ ) and impaired (right; $n=7$ ) glucose utilization.

\section{Insulin-induced hypoglycaemia}

\section{Blood glucose}

The blood glucose nadir was significantly lower in control patients compared with the transplant recipients $(1.6 \pm 0.1$ vs $2.5 \pm 0.3 \mathrm{mmol} / \mathrm{l} ; \mathrm{p}<0.05$; Fig. 6 ). The fall in blood glucose was somewhat slower in the recipients than in the control subjects. Blood glucose recovery was very similar in both groups. In two patients tested 12 months posttransplant comparable blood glucose nadirs and the same rate of glucose decline and recovery (up to $60 \mathrm{~min}$ ) with those of the control subjects were measured.

\section{C-peptide}

C-peptide levels were much higher in organ recipients early and late posttransplant than in healthy subjects indicating insulin resistance and/or diminished renal C-peptide clearance. However, C-peptide was similar suppressible in 
the three subgroups (controls: $\Delta=1.3 \pm 0.1 \mathrm{ng} / \mathrm{ml}$; recipients: $\Delta=2.3 \pm 0.3$ and $2.1 \mathrm{ng} / \mathrm{ml}$ early and late posttransplant; $\mathrm{p}<0.01$ ).

\section{Glucagon}

Basal glucagon was significantly higher in normal individuals $(191.2 \pm 32.6 \mathrm{pg} / \mathrm{ml})$ than in transplant patients $(86.6 \pm 11.2 \mathrm{pg} / \mathrm{ml} ; \mathrm{p}<0.01)$. There was a rapid release during hypoglycaemia reaching a maximal incremental glucagon response $(\Delta \max )$ in control subjects $(101.5 \pm$ $20.9 \mathrm{pg} / \mathrm{ml})$ and in transplant patients $(69.3 \pm 13 \mathrm{pg} / \mathrm{ml})$ which, however, was much greater in the control subjects. There was no improvement of glucagon response to hypoglycaemia 12 months postransplant.

\section{Catecholamines}

Epinephrine and norepinephrine release during hypoglycaemia was significantly reduced in pancreas/kidney recipients when compared to the healthy control subjects (Fig. 5). There was a tendency toward improved catecholamine response 12 months after transplantation, but due to the small number of patients tested $(n=2)$ the data are only preliminary.

\section{Growth hormone and prolactin}

Basal growth hormone was very similar in both groups (Fig. 5) but was less stimulated in the pancreatic recipients when compared to the control subjects. The two patients tested 12 months post-transplant showed a marked stimulated growth hormone release.

Prolactin in the basal state was higher in the recipients and could not be stimulated during hypoglycaemia. This defective hormone release could not be demonstrated 12 months after pancreatic grafting.

\section{Cortisol}

Cortisol release is difficult to judge since most of the patients received prednisone for immunosuppression ( 4 to $16 \mathrm{mg}$ daily; the last dose $24 \mathrm{~h}$ prior to the test) and therefore the endogenous cortisol release was partially suppressed. One year posttransplant the two recipients tested had no further glucocorticoid medication and revealed a normal basal and stimulated cortisol release.

\section{Discussion}

After successful pancreatic and kidney transplantation daily blood glucose and glycosylated haemoglobin can be normalized for many years. However, oral and intravenous glucose tolerance are impaired in 30 to $50 \%$ of the recipients in this cross-sectional analysis. One of the reasons for the rather high rate of impaired glucose utilization is the experimental set-up in which maximal glucose doses were used $(100 \mathrm{~g}$ orally and $0.5 \mathrm{~g} / \mathrm{kg}$ i.v.), and the criteria for normalization of glucose tolerance were very strict. The impaired glucose disposal might be due to di- minished islet cell mass as indicated by significant reduction of insulin release after glucose challenge rather than peripheral insulin resistance. The reduced islet mass which is very important in glucose homeostasis (Weir et al. 1990) might be caused by ischaemic injury perioperative-
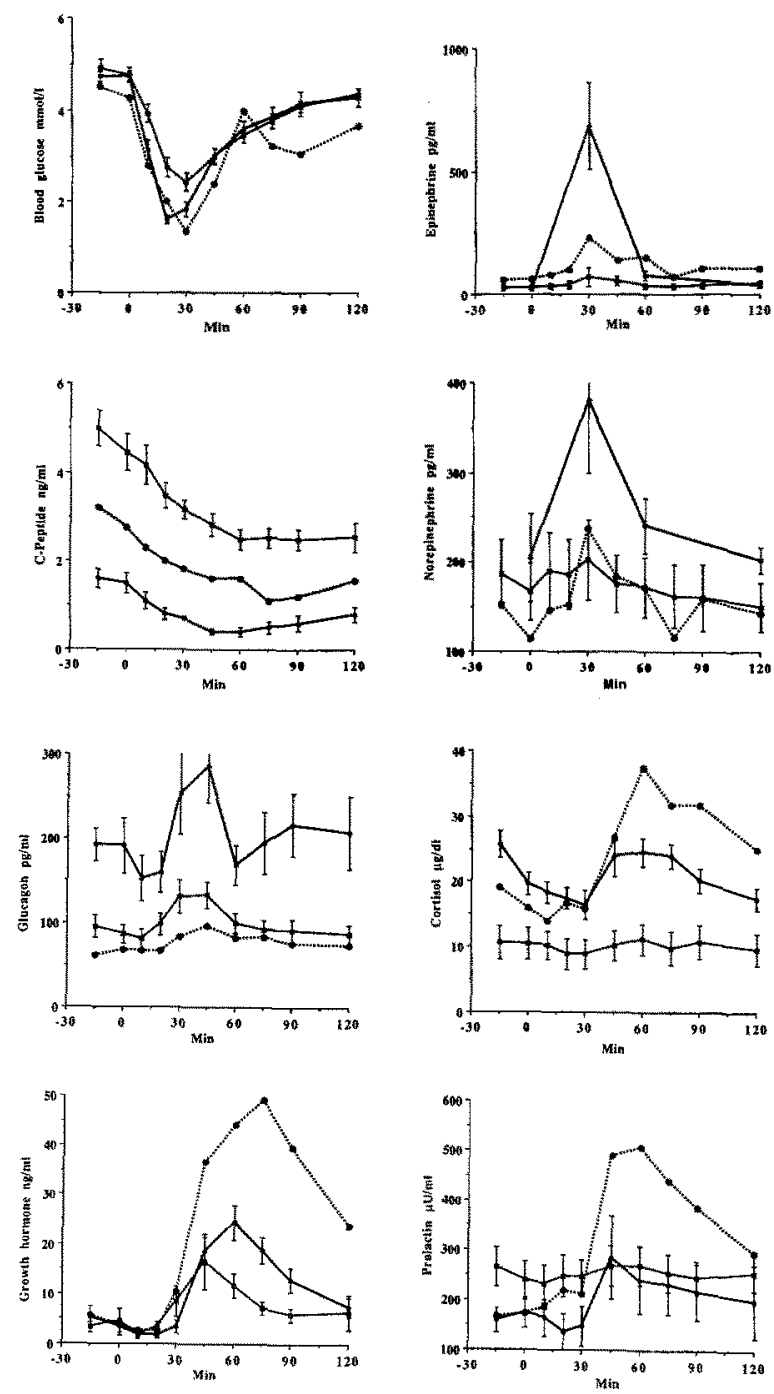

Fig. 6. Blood glucose, C-peptide, growth hormone, prolactin, glucagon, cortisol, and catecholamine before and after regular insulin as bolus i.v. $(0.075 \mathrm{IU} / \mathrm{kg})$ in healthy control subjects $(n=8 ; \bullet)$ and in graft recipients $2-4(n=20 ; n \cdots v)$, and $12(n=2 ; \cdots \bullet)$ months post-transplant.

ly, loss of Beta-cells by post-operative pancreatitis and/or rejection episodes. Recurrence of the autoimmune process (Sutherland et al. 1984) in these patients is rather improbable since there was a high degree of HLA-mismatching. The transplantation of only a pancreas segment rather than the whole organ is probably less important, since only $25 \%$ of the recipients in our study with normal 
glucose tolerance had a whole pancreas graft while the others received prolamine duct occluded pancreatic segments. This observation is supported by findings of the Stockholm and Oslo groups comparing the metabolic outcome of pancreas segments vs whole organ recipients (Tydén et al. 1989).

Assessment of glucose homeostasis by oral glucose tolerance tests or mixed meals in pancreas recipients with severe secondary diabetic complications might be questionable, since autonomic dysfunction with clinically relevant gastroparesis is common in those patients (Nusser et al. 1988). Therefore, intravenous glucose tolerance tests eliminating this potential problem are desirable. When 21 patients of our study group were tested, twelve (57\%) showed corresponding test results for oral and intravenous glucose load, while $29 \%$ revealed impaired oral glucose tolerance with normal i.v. glucose tolerance and $14 \%$ vice versa. The statement of normalization of glucose metabolism in pancreas recipients therefore can only be relevant when the technical details of the kind of testing are clearly defined.

Normal glucose metabolism is achieved at the expense of basal and stimulated hyperinsulinaemia. The higher insulin levels are mainly due to the systemic rather than the physiological portal venous drainage of islet cell secretory products (Diem et al. 1990a) with reduced first pass hepatic extraction of insulin (Eaton et al. 1983). However, as discussed by Diem et al. (1990a), basal elevated insulin and C-peptide levels in pancreas recipients may be a physiological response by the graft to increased glucose output from the liver. But hepatic glucose production both basal and post insulin clamp have been reported as being not different from healthy control subjects in Type 1 diabetic patients after combined kidney and pancreas transplantation (Luzi et al. 1990). Hyperinsulinaemia might therefore reflect, at least to some extent, peripheral insulin resistance mainly caused by the steroid medication (Baron et al. 1987), which most of our patients received. However, that hyperinsulinaemia is not a prerequisite to achieving normal glucose disposal in heterotopic allogenic pancreas recipients is supported by our findings showing that $52 \%$ of the grafted patients had normal oral glucose tolerance plus a normal insulin secretory profile. In view of the potential vascular risk of chronic hyperinsulinaemia (Jarret 1988) normal basal and postprandial insulin levels have to be one of the aims of pancreatic grafting.

Pancreatic polypeptide, which is secreted after arginine stimulation but not after glucose load in healthy subjects (Glaser et al. 1980; Schwartz 1983) could be slightly stimulated by glucose but not by arginine in pancreas recipients. The significantly higher PP levels in graft recipients when compared to healthy control subjects is probably due to a reduced renal clearance. Pancreatic polypeptide responses to hypoglycaemia were significantly diminished in graft recipients compared with control subjects (Diem et al. 1990b). However, pancreatic polypeptide values did not differ significantly in graft recipients and non-recipient Type 1 diabetic subjects. It was therefore suggested that secretion of this hormone occurs from the native pancreas only (Diem et al. 1990b). Since pancreatic polypeptide release requires innervation of the pancreas (Schwartz 1983) this hormone seems not to be an adequate measure of graft function. However, if in longitudinal studies the levels of hPP increase in pancreas recipients this might indicate reinnervation of the grafted organ.

Defective hormonal counterregulation after insulin-induced hypoglycaemia has been reported in insulin-dependent diabetes (Bolli et al. 1983; Amiel et al 1987). This might be a serious problem for the patient and reduces the qualitiy of his/her life. Pancreatic grafting is therefore also aimed at improving or even restoring the deranged counterregulation of hypoglycaemia. There are only a few reports on stress-hormone release and glucose-regulatory response to insulin-induced hypoglycaemia (Bosi et al. 1988; Landgraf et al. 1989; Diem et al. 1990b). In contrast to recent data (Diem et al. 1990b) basal glucagon and its responses to insulin-induced hypoglycaemia were markedly lower in the pancreas recipients under study compared with the healthy control subjects. One of the reasons might be that the glucose nadir after insulin injection was significantly lower in the control subjects than in the patients. However, this does not explain the lower basal glucagon values. In addition, the decreased glucagon responsivity in graft recipients is only seen to glycopaenic signalling but not observed after arginine stimulation. Normal substrateregulated glucagon release can be demonstrated not only for arginine-provoked release, but also for glucose-induced hormone suppression, indicating that the autonomic nervous system is not necessary for the glucagon release mechanisms. However, all data concerning glucagon release are difficult to interpret since it is not known, how much circulating glucagon is coming from the native gland and how much is released by the grafted pancreas.

Despite hypoglucagonaemia and a significant reduction in catecholamine release glucose recovery from hypoglycaemia was comparable to normal subjects. The blunted response of epinephrine and norepinephrine release in our patients indicates severe autonomic dysfunction which could be demonstrated in all recipients by cardiac autonomic neuropathy. Since many patients of Diem et al. (1990b) were studied 3 months posttransplant which is comparable to our study protocol their findings of normal epinephrine levels before and during insulin tolerance testing can only be interpreted by differences in patient selection. The prospective analysis of two of our patients - although still very preliminary - shows that defective hormonal counterregulation especially of glucagon and catecholamines cannot be restored by 12 months after transplantation.

From these studies it can be concluded that longterm improvement of the deranged diabetic metabolism is possible after successful pancreatic grafting. However, in long-standing diabetes some aspects of the metabolic disturbances such as defective counterregulatory responses cannot be reversed easily and due to the necessary chronic immunosuppression insulin resistance might appear or persist. Therefore, pancreatic grafting should only be performed in well-selected patients and in centres with the possibility of a multidisciplinary follow-up of the patient. 
Acknowledgements. We are indebted to the nursing and laboratory staff of our hospitals for excellent patient care and technical assistance. We also would like to thank Ms. F. Haag for the illustrations and Ms. R. Solymar for help with the preparation of the manuscript. The work was supported in part by grants from Hoechst $A G$, Frankfurt, and Boehringer Mannheim, FRG.

\section{References}

Amiel SA, Tamborlane WV, Simonson DC, Sherwin RS (1987) Defective glucose counterregulation after strict glycemic control of insulin-dependent diabetes mellitus. N Engl J Med 316:1376-1383

Baron AD, Wallace $P$, Brechtel $G$ (1987) In vivo regulation of non insulin-mediated and insulin-mediated glucose uptake by cortisol. Diabetes 36:1230-1237

Bolli GB, De Feo P, Compagnucci P, Cartechini MG, Angeletti G, Santeusanio F, Brunetti P. Gerich JE (1983) Abnormal glucose counterregulation in insulin-dependent diabetes mellitus. Interaction of anti-insulin antibodies and impaired glucagon and epinephrine secretion. Diabetes 32:134-141

Bosi E, Piatti PM, Secchi A, Monti LD, Traeger J, Dubernard JM, Pozza G (1988) Response of glucagon and insulin secretion to insulin-induced hypogycemia in type I diabetic recipients after pancreatic transplantation. Diab Nutr Metab 1:21-27

Diem P, Abid M, Redmon JB, Sutherland DER, Robertson RP (1990a) Systemic venous drainage of pancreas allografts as independent cause of hyperinsulinemia in type I diabetic recipients. Diabetes $39: 534-540$

Diem P, Redmon IB, Abid M, Moran A, Sutherland DER, Halter JB, Robertson RP (1990b) Glucagon, catecholamine, and pancreatic polypeptide secretion in type I diabetic recipients of pancreas allografts. J Clin Invest 86:2008-2013

Dubernard JM, Sutherland DER (eds) (1989) International Handbook of Pancreas Transplantation. Kluwer Academic Publishers, Dordrecht Boston London

Eaton RP, Allen RC, Schade DS (1983) Hepatic removal of insulin in normal man: dose response to endogenous insulin secretion. $\mathrm{J}$ Clin Endocrinol Metab 56:1294-1300

Glaser B, Vinik AI, Sive AA, Floyd JC (1980) Plasma human pancreatic polypeptide responses to administered secretion: effects of surgical vagotomy, cholinergic blockade and chronic pancreatitis. J Clin Endocrinol Metab 50:1094-1099

Groth CG (ed) (1989) Proceedings First International Congress on Pancreatic and Islet Transplantation. Diabetes 38 (Suppl 1) 1-335

Hanssen KF, Dahl-Jørgensen K, Lauritzen T, Feldt-Rasmussen B, Brinchmann-Hansen O, Deckert $T$ (1986) Diabetic control and microvascular complications: the near-normoglycaemic experience. Diabetologia 29:677-684

Heding LG (1979) Radioimmunological determination of pancreatic and gut glucagon in plasma. Diabetologia 7:10-19

Jarrett RJ (1988) Is insulin atherogenic? Diabetologia 31:71-75

Land W, Landgraf R (1987) Clinical pancreas transplantation. - The world experience. Transplant Proc 19 (Suppl 4) 1-102

Land W, Landgraf R, Illner WD, Abendroth D, Kampik A, Jensen U, Lenhart FP, Burg D, Hillebrand G, Castro LA, Landgraf-Leurs MMC, Frey L, Gokel M, Schleibner H, Nusser J, Ulbig M (1987) Clinical pancreatic transplantation using the prolamine duct occlusion technique. - The Munich experience. Transplant Proc 19 (Suppl 4) 75-83

Landgraf R, Nusser J, Scheuer R, Fiedler F, Scheider A, MeyerSchwickerath E, Mäller-Felber W, Illner WD, Abendroth D, Land W (1989) Metabolic control and effect on secondary complications of diabetes mellitus by pancreatic transplantation. Bailliere's Clinical Gastroenterology 3:865-876

Luzi L, Secchi A, Facchini F, Battezzati A, Staudacher C, Spotti D, Castoldi R, Ferrari G, Di Carlo V, Pozza G (1990) Reduction of insulin resistance by combined kidney-pancreas transplantation in Type 1 (insulin-dependent) diabetic patients. Diabetologia 33: $549-556$

Najarian JS, Sutherland DER , Groth CG (Guest Eds) (1990) Second International Congress on Pancreatic and Islet Cell Transplantation. Transplant Proc 22:569-883
Nusser J, Huber RM, Scheuer R, Tatsch K, Kirsch CM, Landgraf R (1988) Pulmonary and esophageal dysfunction as a part of autonomic dysfunction. Diabetologia 31:527A

Ostman J, Gunnarsson R, Groth CG (1988) Metabolic control after pancreas transplantation. In: Groth $C G$ (ed) Pancreatic Transplantation. WB Saunders \& Co, Philadelphia London, pp 291-314

Osei K, Henry ML, O'Dorisio TM, Tesi RJ, Sommer BG, Ferguson RM (1990) Physiological and pharmacological stimulation of pancreatic islet hormone secretion in type I diabetic pancreatic allograft recipients. Diabetes 39:1235-1242

Passon PG, Peuler JD (1973) Original-Einzelisotopen-Radioenzymatischer Assay für Catecholamine. Analyt Biochem 51:618631

Peuler JD, Johnson GA (1977) Simultaneous single isotope radioenzymatic assay of plasma norepinephrine, epinephrine, and dopamine. Life Sciences 21:625-636

Riepl RL, Lehnert P, Scharl A, Hempen I, Fiedler F, Teufel J, Burhol PG (1990) Effect of intraduodenal bile and Na-taurodioxycholate on exocrine pancreatic secretion and on plasma levels of secretin, pancreatic polypeptide, and gastrin in man. Scand J Gastroenterl 25:45-53

Schwartz TW (1983) Pancreatic polypeptide: a hormone under vagal control. Gastroenterology 85:1411-1425

Stalla GK, Giessmann G, Müller OA, Wood WG, Scriba PC (1981) The development of a direct homologous radioimmunoassay for serum cortisol. J Clin Chem Clin Biochem 19:427-434

Sutherland DER, Sibley R, Chinn P, Michael A, Srikanta S, Taub F, Najarian J, Goetz FC (1984) Twin to twin pancreas transplantations: reversal and reenactment of the pathogenesis of type I diabetes. Clin Res 32:56

Tydén G, Brattström C, Bolinder J, Bohman SO, Groth CG, Brekke IB, Holdaas H, Flatmark A (1989) Long-term metabolic control in recipients of segmental pancreas grafts with pancreaticoenterostomy or duct obstruction. Diabetes 38 (Suppl 1) 94-96

Weir GC, Bonner-Weir S, Leaky JL (1990) Islet mass and function in diabetes and transplantation. Diabetes 39:401-405

Werder K v (1975) Wachstumshormone und PRL-Sekretion des Menschen. Urban und Schwarzenberg, Berlin Heidelberg

Professor R. Landgraf

Klinkium Innenstadt

Medizinische Klinik

University of Munich

Ziemssenstrasse 1

8000 Munich

FRG 